\title{
"MALIGNANT LEUKOPLAKIA" OF THE RECTUM : METAPLASTIC BASO-SQUAMOUS CARCINOMA OF THE RECTAL MUCOSA
}

BY

\author{
J. M. DRENNAN AND C. W. A. FALCONER \\ From the Western General Hospital, Edinburgh
}

(RECEIVED FOR PUBliCATION AUGUST 5, 1958)

In 1949 Dukes described an unusual condition which he called "leukoplakia of the rectum, resembling carcinoma." The clinical features and the naked-eye appearance of the lesion were those of carcinoma, but this diagnosis was disproved on histological examination, which showed that the rectal mucosa had been completely replaced by hyperplastic squamous epithelium. The patient, a middle-aged man, was a lunatic, and, for want of other evidence, the epithelial changes were attributed to the practice, common amongst lunatics, of harbouring foreign bodies in the rectum. This case appears to be the only one of its kind in the literature.

We report a second example of squamous-cell metaplasia of the rectum which differs from the other in that the squamous epithelium not only looked malignant but had in fact undergone malignant change, the growth being a carcinoma of mixed squamous and basal cell type.

\section{Clinical History}

A woman, aged 47, was admitted to hospital complaining of rectal discomfort for two weeks and loss of appetite and weight for an indefinite period. Bowel action had always been regular. Examination revealed a stricture 4 in. above the anus and a large ischio-rectal abscess.

The abscess was opened and found to communicate with the rectum at the site of the stricture. A faecal fistula, which developed subsequently, was treated by left iliac colostomy. Biopsy material from the site of stricture showed squamous carcinoma, and the rectum was therefore removed two months later, when the patient's general condition had improved. No intra-abdominal metastases were felt at operation and the primary growth seemed to have been completely eradicated. Eight months later, however, when the perineum was opened to drain a pelvic abscess, it was found that the tumour had recurred locally. Radiotherapy failed to arrest the growth and the patient died of malignant cachexia 16 months from the time of her first admission to hospital. Permission for a necropsy was refused.

Laboratory investigation during the course of her illness included Wassermann and Kahn tests and repeated Frei tests for lymphogranuloma venereum. All were negative.

Operation Specimen of Rectum and Anus (Fig. 1).The mucosa in the upper two-thirds was thin and glazed, with a few small shallow ulcers and

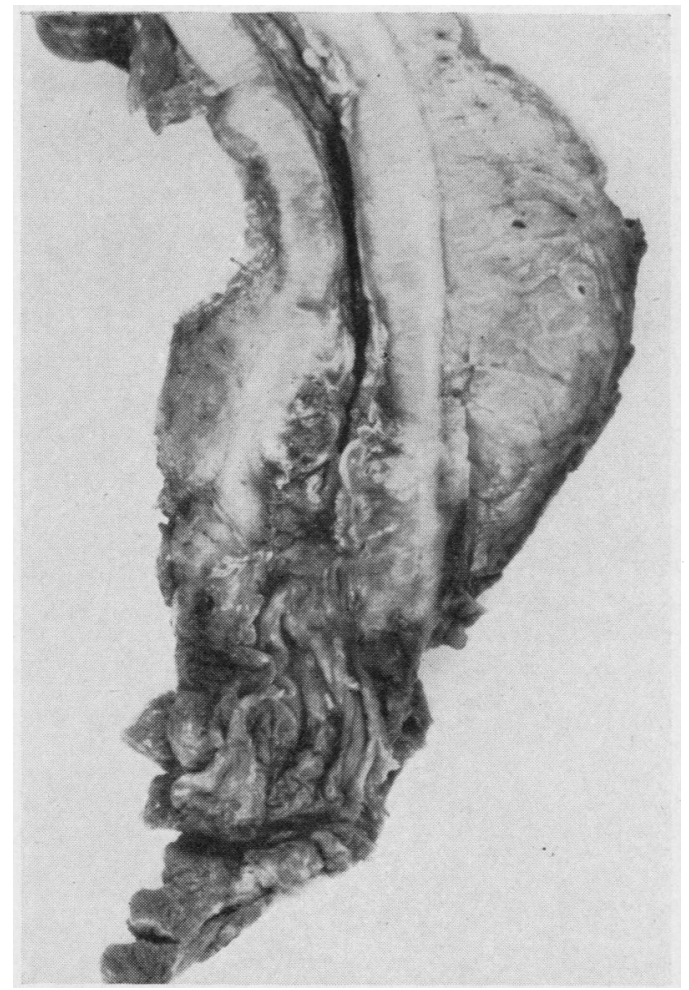

FIG. 1.-The rectum removed at operation, showing the tumour at the lower end. 


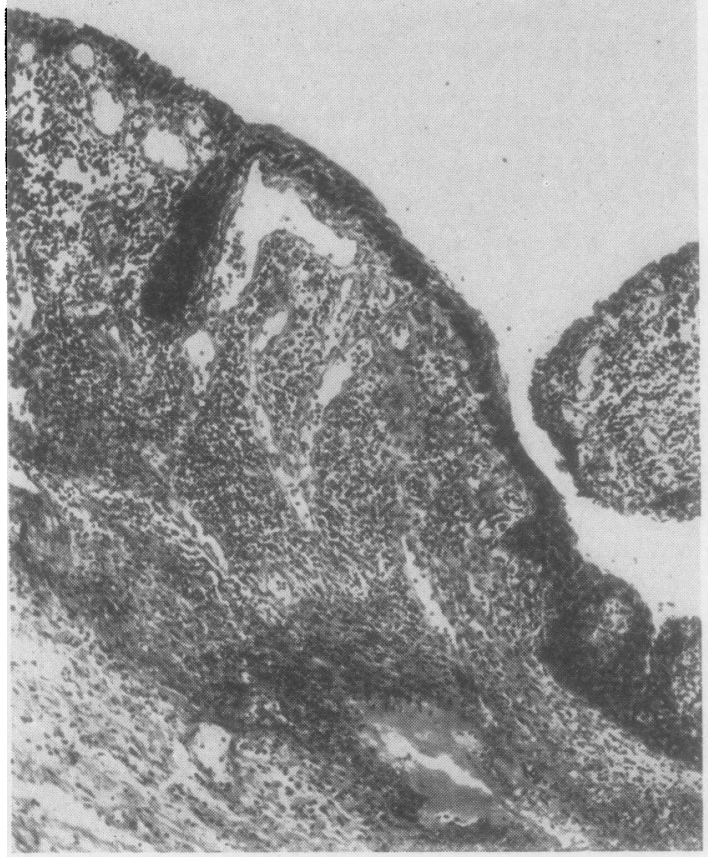

FIG. 2.-Thin, atrophic, metaplastic squamous epithelium in the upper part of the rectum $(\times 75)$.

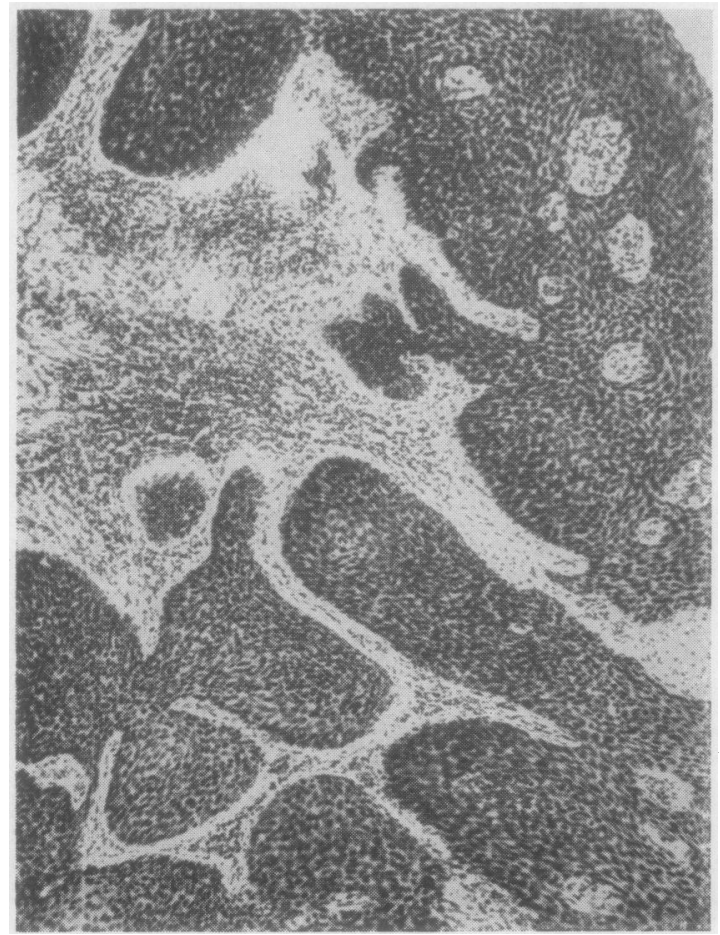

Fig. 4.-An area of tumour showing the pattern of basal cell carcinoma $(\times 75)$.

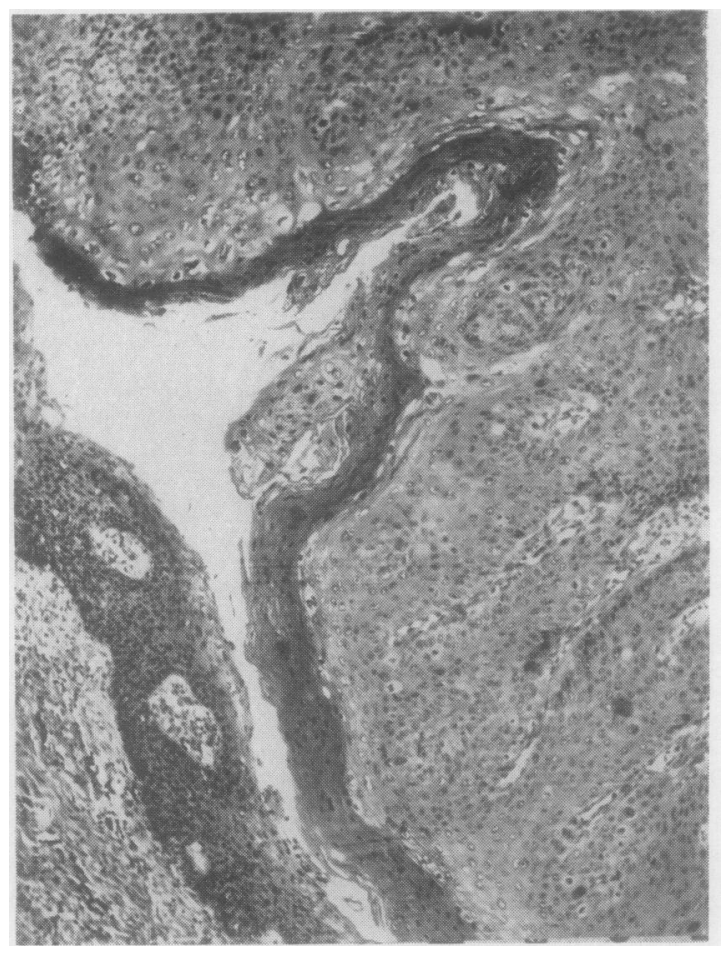

FIG. 3.-Keratinized hyperplastic squamous epithelium above the tumour $(\times 75)$.

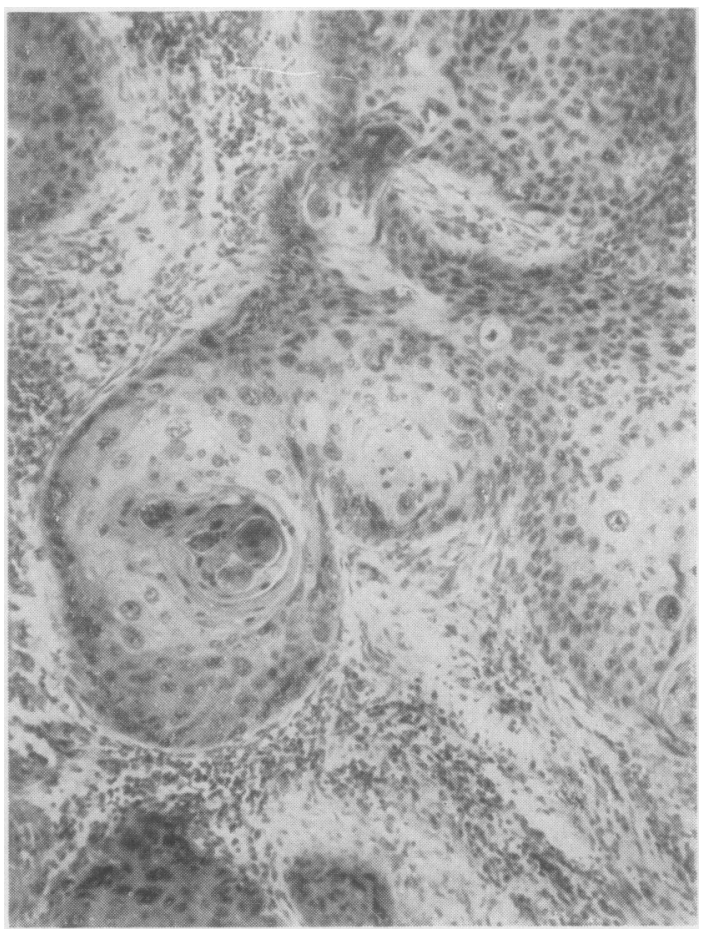

Fig. 5.-An area of tumour showing the pattern of squamous cell carcinoma with epithelial pearl formations $(\times 110)$. 


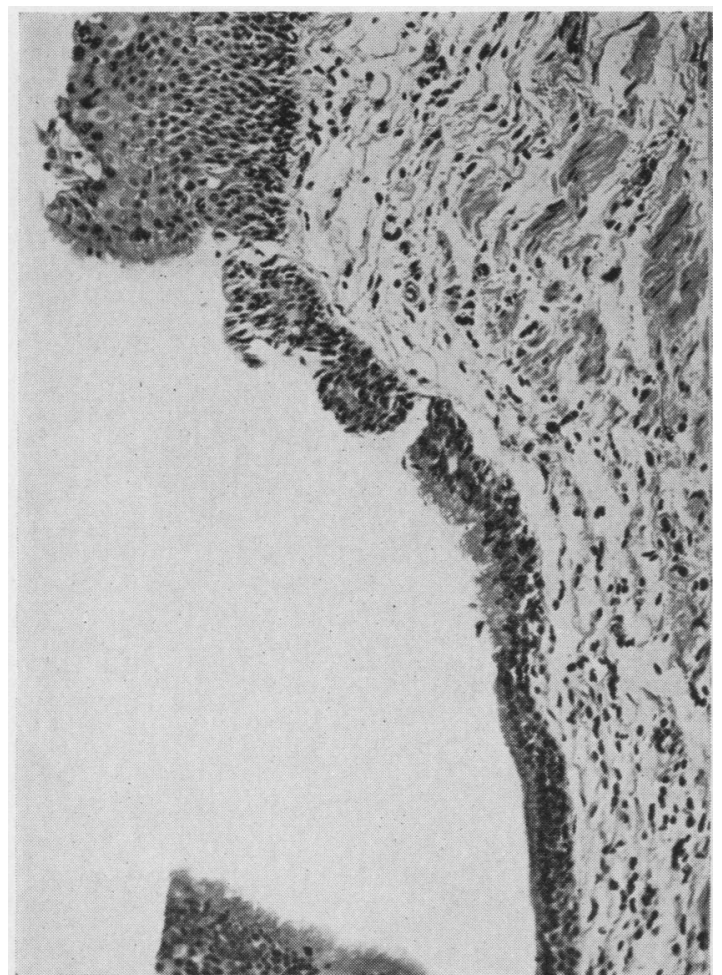

FIG. 6.-Below the tumour: junction of normal columnar cell mucosa (bottom) with metaplastic squamous epithelium (top) $\times 150$ ).

occasional white opaque thickened areas. Lower down, the mucosa became increasingly thickened in a pattern of pearly-white nodules and ridges merging into a fungating tumour which encircled the rectal wall, about 3 in. above the anus. Section at this level showed firm, white tumour spreading from the mucosa into the muscle layer.

Microscopical Examination.-The glandular mucosa was entirely replaced by squamous epithelium, thin and atrophied in the upper part of the specimen (Fig. 2), thick, hyperplastic, and heavily keratinized lower down (Fig. 3). In the neighbourhood of the tumour, atypical cells and mitotic figures became plentiful and irregular hyperplastic areas appeared in the basal and superficial layers of the epithelium. The tumour itself (Figs. 4 and 5) was a mixture of squamous and basal cell carcinoma, both elements being present as in situ and invasive forms. Tumour cells had infiltrated into the muscle of the rectal wall but were not seen in lymphatics or peri-rectal lymph nodes. Below the tumour the lining epithelium resumed the metaplastic squamous form, which in turn gave place to normal columnar cell mucosa (Fig. 6). The inflammatory element in the lesion was low-grade and chronic: superficial granulating ulcers on the mucosa and fibrosis in the submucosa.

\section{Discussion}

The histological findings in this case leave no doubt that the carcinoma arose in pre-existing squamous epithelium and that the primary lesion is similar to that described by Dukes (1949).

In defining the carcinoma as a secondary phenomenon, malignant disease can be excluded as a cause of the leukoplakia. This is necessarily the first step in attempting to elucidate the genesis of the lesion, since malignant disease is the only condition in which squamous change in gastrointestinal epithelium is a recognized, albeit rare, occurrence (Hicks, 1953; Schmidtmann, 1919; Hicks and Cowling, 1955; LeBlanc, Buie, and Dockerty, 1950). As for the other known metaplasia-inducing agents (setting aside their seeming ineffectiveness in the gastro-intestinal tract), there is none which can be identified satisfactorily with the rectal lesion.

Mechanical Irritation.-Trauma caused by a foreign body cannot perhaps be altogether discounted on a patient's denial of perverted habits. But even if this form of mechanical irritation could be established, there is insufficient evidence available for assessing its effect on rectal mucosa. Rectal prolapse, another possible source of mucosal traumatization, is subject to the same difficulty of proof. In experimental animals, rectal prolapse may cause squamous metaplasia and carcinoma (Wells, Slye, and Holmes, 1938), but it is not known to have this effect in man.

Chronic Inflammation.-This can almost be excluded on the short clinical history, and it is worth recalling that squamous metaplasia has not been observed in peptic ulcer, dysentery, colitis, or proctitis, no matter how chronic.

Congenital Malformation.-This is unlikely to leave squamous rests in the rectal mucosa since the rectum completes its development from hind gut before reaching the anal skin. Moreover, there are no reports of congenital squamous rests having been found anywhere in the gastrointestinal epithelium. Finally, there is an illunderstood form of squamous metaplasia which occurs apparently fortuitously in adult life at such diverse and unexpected sites as bursae (King, 1950), pituitary (Biggart, 1949; Hunter, 1955), uterine tube (Plaut and Dreyfuss, 1940), or peritoneum (Crome, 1950). These lesions have all been small inactive foci not subject to malignant change. For the present, it would seem that they resemble rectal leukoplakia only in the mystery of their origin.

Experience with this case prompts the following observations. 
(1) The cause of squamous-cell metaplasia of the rectum is unknown, but it is best regarded as a pre-cancerous state. Malignant change, though perhaps not inevitable, can certainly supervene.

(2) Even when benign, the lesion may be indistinguishable from carcinoma clinically (Dukes, 1949).

(3) Apparently reassuring biopsy reports of simple hyperplastic squamous epithelium should not deflect the surgeon from his proper course of action, which is excision of the rectum.

\section{Summary}

A case of baso-squamous cell carcinoma of the rectum associated with, and believed to be secondary to, widespread squamous metaplasia of the rectal mucosa (leukoplakia of the rectum) is described.
We would like to thank Dr. C. E. Dukes for his courtesy in discussing his case with us.

The photography is the work of Dr. T. C. Dodds, F.I.M.L.T., Head of the Medical Photography Unit, Edinburgh University.

\section{REFERENCES}

Biggart, J. H. (1949). Pathology of the Nervous System, 2nd ed., p. 312. Livingstone, Edinburgh.

Crome, L. (1950). J. Path. Bact., 62, 61.

Dukes, C. E. (1949). Ann. roy. Coll. Surg., 4, 90.

Hicks, J. D. (1953). J. Path. Bact., 66, 570.

- and Cowling, D. C. (1955). Ibid., 70, 205.

Hunter, I. J. (1955). Ibid., 69, 141.

King, E. S. J. (1950). Aust. N.Z. J. Surg., 19, 208.

LeBlanc, L. J., Buie, L. A., and Dockerty, M. B. (1950). Ann. Surg., $131,392$.

Plaut, A., and Dreyfuss, M. L. (1948). Arch. Path. (Chicago), 30, 1089 .

Schmidtmann, Martha (1919). Virchows Arch. path. Anat., 226, 100. Wells, H. G., Slye, M., and Holmes, H. F. (1938). Amer. J. Cancer 33, 223. 